\title{
MODELAGEM DOS CONCEITOS ASSOCIADOS À NOTIFICAÇÃO COMPULSÓRIA DE MAUS TRATOS CONTRA CRIANÇAS E ADOLESCENTES
}

\author{
Modeling Concepts Associated to the Compulsory Reporting of Child and Teenager Abuse \\ Michele Mariana Vieira Ferreira Santos''; Luciana Tricai Cavalini²
}

\begin{abstract}
Resumo A presente dissertação foi defendida no Mestrado Profissional em Saúde Materno-Infantil da Universidade Federal Fluminense (UFF). O objetivo do projeto foi modelar os conceitos da Ficha de Notificação Compulsória de Maus Tratos contra Crianças e Adolescentes, como base para o desenvolvimento de um sistema computadorizado de monitoramento da ocorrência deste tipo de violência, de acordo com as especificações openEHR.
\end{abstract}

Palavras-chave: Registros Eletrônicos de Saúde, Notificação Compulsória, Maus-Tratos Infantis

\begin{abstract}
This MSc thesis was defended at the Professional Masters Course in Maternal and Child Health at the Fluminense Federal University (UFF), aiming the modelling of concepts related to the Children and Teenager Abuse Reporting Form as a basis for the development of an application for monitoring the occurrence of such type of violence, according to the openEHR specifications.
\end{abstract} Keywords: Electronic Health Records, Mandatory Reporting, Child Abuse

Introdução: Segundo dados da OMS, a violência cometida contra crianças e adolescentes é de tal forma relevante, que já se tornou um problema de saúde pública. Na garantia dos direitos desse grupo etário, o SUS preconiza prioridade de atenção responsabilizando os profissionais de saúde, entre outros, na notificação de suspeita de maus tratos sofridos pelos mesmos. Embora isso aconteça, na prática, enfrentamos dificuldades diversas no que tange à notificação de violência por parte desses profissionais.

Objetivo: Modelar os conceitos da ficha de notificação compulsória de maus tratos como base para o desenvolvimento de um sistema computadorizado de monitoramento da ocorrência do fato.

Método: A ficha de notificação foi pré-selecionada para a modelagem dos conceitos a serem incluídos em um sistema computadorizado de detecção de maus tratos contra crianças e adolescentes. A modelagem do conhecimento utilizada é baseada nos princípios da modelagem multinível de sistemas de informação em saúde.

Resultados: O mapeamento do modelo de dados da Ficha de Notificação com os arquétipos openEHR encontrou 27 correspondências, sendo que 22 foram consideradas totais e outras 5 parciais.

Discussão: No campo "Dados da Violência", nenhum dos itens "Se ocorreu violência, qual o tipo" e "Se ocorreu penetração, qual o tipo" encontraram arquétipos correspondentes disponível no CKM, optou-se por modelar este grupo de conceitos em um arquétipo.

Conclusão: A modelagem dos conceitos da ficha poderá nos auxiliar futuramente no diagnóstico realizado por computador e nos fornecer uma informação em rede protocolada de como o profissional pode identificar tais casos e intervir em tempo, protegendo e preservando as crianças e adolescentes.

1. Psicóloga da Secretaria Municipal de Educação de Três Rios - Especialização em Gestão Hospitalar; 2. Professora Adjunta do Departamento de Tecnologias da Informação e Educação em Saúde - Faculdade de Ciências Médicas - Universidade do Estado do Rio de Janeiro - Doutorado em Saúde Pública. 